\title{
A custom acoustic emission monitoring system for harsh environments: application to freezing-induced damage in alpine rock walls
}

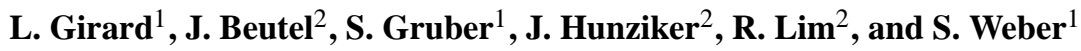 \\ ${ }^{1}$ Glaciology \& Geomorphodynamics, Department of Geography, University of Zurich, Zurich, Switzerland \\ ${ }^{2}$ Computer Engineering and Networks Laboratory, Swiss Federal Institute of Technology Zurich, Zurich, Switzerland \\ Correspondence to: L. Girard (lucas.girard@geo.uzh.ch)
}

Received: 29 May 2012 - Published in Geosci. Instrum. Method. Data Syst. Discuss.: 15 June 2012

Revised: 3 October 2012 - Accepted: 4 October 2012 - Published: 5 November 2012

\begin{abstract}
We present a custom acoustic emission (AE) monitoring system designed to perform long-term measurements on high-alpine rock walls. AE monitoring is a common technique for characterizing damage evolution in solid materials. The system is based on a two-channel AE sensor node (AEnode) integrated into a wireless sensor network (WSN) customized for operation in harsh environments. This wireless architecture offers flexibility in the deployment of AE-nodes at any position of the rock wall that needs to be monitored, within a range of a few hundred meters from a core station connected to the internet. The system achieves near real-time data delivery and allows the user to remotely control the $\mathrm{AE}$ detection threshold. In order to protect AE sensors and capture acoustic signals from specific depths of the rock wall, a special casing was developed. The monitoring system is completed by two probes that measure rock temperature and liquid water content, both probes being also integrated into the WSN. We report a first deployment of the monitoring system on a rock wall at Jungfraujoch, $3500 \mathrm{~m}$ a.s.l., Switzerland. While this first deployment of the monitoring system aims to support fundamental research on processes that damage rock under cold climate, the system could serve a number of other applications, including rock fall hazard surveillance or structural monitoring of concrete structures.
\end{abstract}

\section{Introduction}

Acoustic emission monitoring is a powerful non-destructive method to characterize progressive damage and deformation processes of materials that has a wide range of possible applications in engineering, material sciences, and also for the detection of potential natural hazards (Michlmayr et al., 2012). Acoustic emissions (AEs) are transient elastic waves generated by the rapid release of energy within a material (Hardy, 2003). Most of the processes that generate AEs are related to an increase of material damage (Lockner et al., 1991; Scholz, 1968), such as crack formation, friction between solid surfaces, or grain motion/rearrangements in granular materials. The range of frequencies that concerns $\mathrm{AE}$ studies is $10 \mathrm{kHz}-1 \mathrm{MHz}$. As a consequence, AEs are typically generated by sources or flaws varying from submillimeter (i.e. grain size) up to centimeter sizes.

Our goal is to use this long-known technique to continuously monitor AEs in steep mountain rock walls (i.e. having a slope angle larger than $50^{\circ}$ ) during a multi-year-long period. The rationale for acquiring such data is to improve our understanding of the processes that mechanically damage rock in cold climate, such as freezing (Walder and Hallet, 1985) and thermal gradients (Hall et al., 2002), as well as their contribution to weathering (Matsuoka and Murton, 2008) and rock falls (Gruber and Haeberli, 2007). Monitoring AEs generated within a rock wall will allow us to infer the conditions and the characteristics of rock damage increase, in response to these different sources of mechanical loading. A great challenge in understanding the operation of rock damage under natural conditions is related to the large spatial and temporal heterogeneity in the rock thermal conditions as well as in the rock physical properties (e.g. fracture state, moisture content, thermal and hydraulic conductivity). We therefore expect the 
investigation of diurnal and seasonal cycles of rock damage to be important for the robust transfer of theoretical insight to field conditions. Finally, achieving this transfer also requires investigation of rock damage at different positions spanning the main dimensions of variability.

AE monitoring techniques have been used in earlier studies to understand the evolution of different gravitational instabilities such as large rockslides (Lacroix and Helmstetter, 2011; Helmstetter and Garambois, 2010; Gaffet et al., 2010), rock wall (Levy et al., 2011) and rock slope instabilities (Cheon et al., 2011), or mudslides (Amitrano et al., 2007; Walter et al., 2012). Most of these studies have used geophones or accelerometers instead of AE sensors. The principle of such measurements, often referred to as microseismic monitoring, is similar to AE monitoring, although it concerns a lower frequency band, typically extending from $1 \mathrm{~Hz}$ to a few hundred $\mathrm{Hz}$. The reason for this is that natural slopes are generally large (hundreds of meters) and include discontinuities. Under such conditions, AEs generated within the unstable slope/wall are strongly attenuated and may not be detected if the sensor is too far away from the source. In this study, we focus on near-surface mechanisms (up to $1 \mathrm{~m}$ depth) that progressively damage rock, such as freezing and thermal gradients. In order to achieve this, the monitoring system should be suitable to detect early stages of damage, i.e. AEs generated by sources of small (typically millimeter) size. As we focus on progressive damage mechanisms that occur in the near-surface, the spatial detection range of $\mathrm{AE}$ monitoring (on the order of a meter) is sufficient. The feasibility of using AE monitoring for this purpose was assessed by carrying out a pilot study which yielded promising results (Amitrano et al., 2012).

Current commercial AE platforms in this frequency range are typically based on hardwired, centralized data collection of weight and power requirements that are too large for our application. Previous studies that have monitored AEs in outdoor conditions have been restricted to short time periods, during which the monitoring system was carefully protected from the changing environmental conditions in a nearby heated building, for example (Cheon et al., 2011; Amitrano et al., 2010, 2012).

Recently, a few wireless AE platforms, based on cellphone communication, have been created to perform structural monitoring of concrete or steel structures such as bridges (Ledeczi et al., 2009; Grosse et al., 2008). To date, none of the existing AE systems allow long-term monitoring under harsh outdoor conditions with autonomous power supply. Our application brings a number of new challenging requirements that motivate the development of a new $\mathrm{AE}$ acquisition system.

The first challenging aspect is a series of requirements that arises from the harsh environmental conditions in high-alpine rock walls, demanding a proper ruggedization of the system. The need for multi-year continuous measurements requires energy harvesting (e.g. using a solar panel) and optimizing for low-power consumption. Additionally, as several positions need to be instrumented in remote mountain areas that may not all provide reliable cell-phone communication, the use of a wireless sensor network (WSN) brings a number of advantages. In a WSN, spatially-distributed autonomous sensors, referred to as nodes, cooperatively pass their data through the network to a main station. This offers flexibility in the choice of sensor positioning as only the main station needs to be connected to the Internet. The near real-time transmission of data measured by the nodes of the WSN allows the user to rapidly detect problems that can affect the sensors. This is an important advantage to achieve highquality, long-term monitoring.

The second challenging aspect is related to the installation of acoustic sensors on the rock wall. In the frequency range covered by $\mathrm{AE}$ monitoring, material attenuation is such that most AEs are attenuated after approximately a meter of propagation. A possible solution to overcome the attenuation problem is to use a waveguide (Dixon et al., 2003; Cheon et al., 2011). This solutions has been considered for our application, but experiments have showed that the best results were obtained when installing the sensors as close as possible to the point of interest, inside a borehole (Weber et al., 2012).

In order to address these two main challenges, we have developed a custom AE monitoring system that consists of (i) the AE-node, a two-channel acquisition system that transmits AE data using a WSN customized for operation in harsh environments (Beutel et al., 2009; Hasler et al., 2011) and (ii) a special casing that houses an $\mathrm{AE}$ sensor inside a borehole and allows it to retrieve acoustic signals from specific depths of a rock wall (e.g. 10 and $50 \mathrm{~cm}$ ) (Weber et al., 2012).

The measurement system is completed by two additional probes that measure rock temperature and moisture content at different depths. Similarly to AE data, rock temperature and moisture data are also transmitted through the WSN. The work presented in this paper was done as part of a joint geoscience and engineering effort (Beutel et al., 2009) which aims to serve as prototype for future systems of wider applicability in research and hazard surveillance. In this context, the difficult environmental conditions at high elevation serve as a benchmark for system robustness.

In this paper, we first detail the requirements for the $\mathrm{AE}$ monitoring system from a geoscientific perspective and translate them in terms of technical specifications. Then we present the characteristics and performances of the custom $\mathrm{AE}$ acquisition system that we have developed and the design of the casing that houses the AE sensors. We also briefly detail the characteristics of the temperature and capacitance probes that complete the monitoring system. Finally, we report on the first field deployment and the performances of the measurement system on a rock wall located at Jungfraujoch, $3500 \mathrm{~m}$ a.s.l, Switzerland. 


\section{AE system: requirements and specifications}

\subsection{Geoscientific requirements}

A likely important source of rock damage in cold environments is related to the freezing of water contained in rock pores and cracks (Matsuoka and Murton, 2008). Frost damage can be caused by the volumetric expansion $(\sim 9 \%)$ of freezing water, but it can also occur through the growth of ice filled discontinuities fueled by the migration of liquid water from unfrozen parts of the rock (Walder and Hallet, 1985). This second mechanism, referred to as ice segregation, occurs during periods of sustained freezing and it is theoretically predicted to be most effective in producing crack growth when temperatures range from $\sim-4$ to $-15^{\circ} \mathrm{C}$. Our goal is to design a measurement system suitable to test and characterize the operation of these two frost weathering processes. This explains the motivation for monitoring in highaltitude rock walls in the Alps, in which the thermal conditions should allow both processes to operate: close to the surface, periods of sustained freezing are encountered in winter, as well as a number of freeze-thaw cycles during the rest of the year (e.g. Hasler et al., 2011).

The harsh environmental conditions prevailing in highaltitude rock walls imply a first series of requirements for the system to be designed: operating temperature range from -30 to $+40^{\circ} \mathrm{C}$, protection from lightning and from surface damage that could be caused by falling rocks, ice or snow avalanches.

As freezing is believed to damage and fracture rock up to several meters deep (Murton et al., 2006), it appears important that the monitoring system allows capturing of AE signals from a significant depth of the rock wall, and provides an estimation of depths of AE sources. Such measurements require installing several sensors close to each other, at different depths. However, one should keep in mind that a robust installation of $\mathrm{AE}$ sensors requires a borehole for each sensor (see Sect. 4), which inevitably increases the disturbance of the rock mass investigated. In order to minimize this disturbance, the installation of the sensors inside the boreholes should exclude water flow and ice formation on the borehole walls, i.e. the boreholes should be sealed. To further ensure a long-term monitoring ability, the installation protocol should allow exchanging the sensor installed in the borehole in case of sensor failure.

The strategy that we have chosen is to work with only two sensors per monitoring position. This choice was motivated as a trade-off between having just enough sensors to provide a rough zonation of source depths, while limiting environmental disturbance. The installation depth of the two sensors, at 10 and $50 \mathrm{~cm}$ depth, has been also chosen as a compromise between having the sensors close enough to be able to detect some AEs on both sensors and having the sensors sufficiently distant from each other to monitor AEs in two very different thermal regimes of the rock mass: the near-surface (large daily temperature fluctuations and high number of freezethaw cycles) and the greater depth (long periods of sustained freezing).

In order to finalize the requirements of the $\mathrm{AE}$ platform to be designed for our multi-year monitoring objective, we first carried out a four-day pilot experiment using a commercially available AE acquisition system (Amitrano et al., 2012). During this experiment, a six-channel acquisition system was used to monitor AEs at the surface of a rock wall, which encountered daily freeze-thaw cycles. Based on the expected size of sources of AEs, piezoelectric AE sensors with an operating frequency range of $10-150 \mathrm{kHz}$ with peak sensitivity at $60 \mathrm{kHz}$ were chosen. The sensors were pressed on steel plates and screwed onto extension bolts anchored about $5 \mathrm{~cm}$ deep in rock. The high number of events detected on all channels, as well as the statistical properties of AEs, proved that the type of sensors were appropriate for this application (Amitrano et al., 2012).

\subsection{Technical specifications}

In order to be able to monitor AEs at different locations of a rock wall, we chose to design the two-channel $\mathrm{AE}$ acquisition system as the node of a WSN, hence the name AE-node. The AE-node will use the WSN system developed as part of the PermaSense project, customized for operation in harsh environments (Beutel et al., 2009). This will allow a deployment of up to 25 nodes per site with up to $150 \mathrm{~m}$ spacing between nodes.

We design the AE-node to function with piezoelectric sensors (R6 $\alpha$ from Physical Acoustics Ltd, UK) of similar characteristics to the ones used during the pilot experiment. The peak resonance of the R6 $\alpha$ sensors lies at a frequency of $55 \mathrm{kHz}$, with a loss of less than $10 \mathrm{~dB}$ in a range of 35 to $100 \mathrm{kHz}$. In order to limit the required signal processing capabilities, we choose to base the acquisition system on a $500 \mathrm{kHz}$ sampling rate at 16 bits resolution. This sampling frequency ensures the required time precision needed to perform a zonation of the detected AE events. Zonation consists in assessing if a given AE event was detected by one or both channels of the AE-node, providing a rough estimation of its source depth. As the speed of primary waves (P-waves) in rock is about $5 \mathrm{~km} \mathrm{~s}^{-1}$ (Table 1) and the sensors will be mounted at a distance of $40 \mathrm{~cm}$, the arrival time differences of sources detected by both sensors will be on the order of 0 $80 \mu$ s. In comparison, the $500 \mathrm{kHz}$ sampling frequency gives an accuracy on the arrival time of an AE event up to $2 \mu$ s.

The monitoring of high frequency acoustic signals inherently generates high data volumes. As battery operated and energy optimized wireless networks do not offer high data rates, we had to come up with a solution that captures as much information as needed for the investigation of rock damage while fitting into the scope of a low power wireless system. By preprocessing the acquired data directly on the acquisition system, we are able to drastically reduce the 
Table 1. Relevant properties of materials used in the construction of the AE casing, after Weber et al. (2012). P-wave speed is estimated as $C=\sqrt{\frac{Y}{\rho} \frac{1-v}{(1+2 v)(1+v)}}$. The transmission coefficient relative to gneiss is calculated as $\alpha_{\mathrm{tr}}=1-\left(\left(Z_{x}-Z_{\mathrm{g}}\right) /\left(Z_{x}+Z_{\mathrm{g}}\right)\right)^{2}$, where $Z_{x}=\rho_{x} C_{x}$ is the acoustic impedance of material $x$ and $Z_{\mathrm{g}}$ that of gneiss.

\begin{tabular}{lllll}
\hline Material & Gneiss & Aluminum & POM & Geo-Gel \\
\hline Density $\rho\left(\mathrm{g} \mathrm{cm}^{-3}\right)$ & 2.7 & 2.7 & 1.4 & 1.0 \\
Young Modulus $Y(\mathrm{GPa})$ & 56 & 70 & 3 & 0.1 \\
Poisson ratio $\nu$ & 0.28 & 0.35 & 0.35 & 0.45 \\
P-wave speed $C\left(\mathrm{~km} \mathrm{~s}^{-1}\right)$ & 5.1 & 6.4 & 1.8 & 0.6 \\
Transmission coef. $\alpha_{\text {tr }}$ & 1 & 0.99 & 0.53 & 0.16 \\
\hline
\end{tabular}

needed bandwidth by transmitting only parameters of the analyzed AE signal through the WSN. AE parameters, which constitute the most important data for analyses, can thus be transmitted in near real-time, while the waveforms of $\mathrm{AE}$ events, which can be useful for in-depth analyses, are stored locally on the node and can be recovered when needed. The signal analysis is triggered by the crossing of a threshold, defining the beginning of an event, and ends when the threshold has not been exceeded for a given (post-trigger) time. The parameters transmitted for each event and commonly used in AE studies (e.g. Hardy, 2003) are the following (Fig. 1):

- Count: the number of times that the signal exceeds the threshold value.

- Length: the amount of time between the first threshold crossing and the end of the post-trigger time.

- Amplitude: the maximum signal amplitude.

- Rise Time: the time interval between the first threshold crossing and the time of the peak amplitude.

- Energy: the signal energy contained in the event, i.e. the sum of the squared sample amplitudes.

Additionally, we choose to design the system so that the threshold and post-trigger values (Fig. 1) can be adjusted in operation, i.e. with command messages sent to the AE-node.

During the pilot experiment, the number of events detected differed strongly from one location to the other (up to a factor of ten) (Amitrano et al., 2012). The AE activity was also observed to be intermittent, with long quiet periods followed by short bursts of activity with high event rates. In such intermittent dynamics, the mean event rate ( 3 events per minute) is not representative of the extreme loads that the system needs to handle during bursts of activity (up to 300 events per second). In order to cope with high event rates, a strategy is defined so that the system can capture events at 3 different granularity levels, adapted to different event rate loads. Under light load (level 1), the system computes the AE parameters

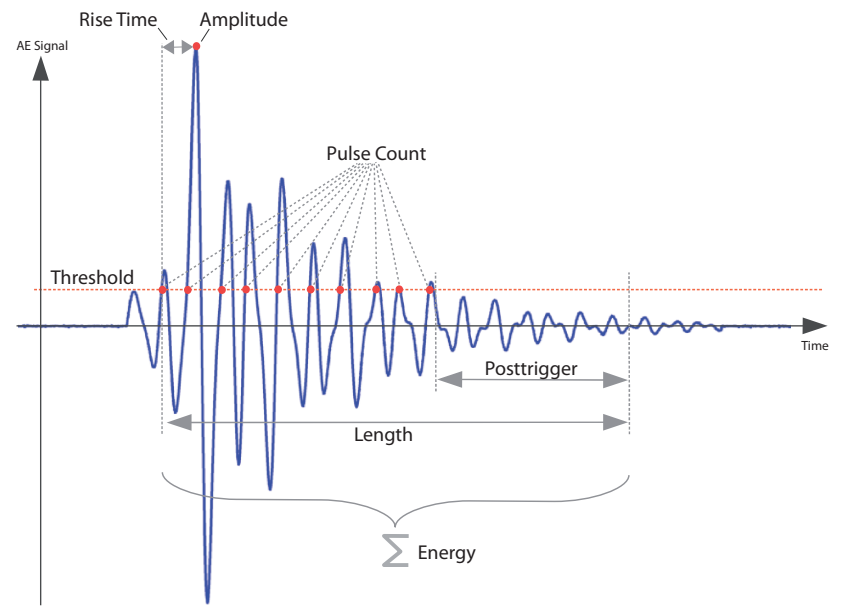

Fig. 1. Extracted parameters from an AE signal.

and saves the whole waveform of an event to the local storage. If event rates become quickly higher (level 2), the signal is only parameterized. For the rare case where the event rate is too high to allow signal parameterization (level 3), the events are only counted. This processing strategy will allow the system to run stably even under heavy load conditions.

\section{A custom acquisition system: the AE-node}

\subsection{Architecture}

The two main tasks of the AE-node system are (i) to acquire and process the data stream coming from the acoustic sensor and (ii) to communicate with the low power WSN. Both tasks have very different requirements. Data acquisition demands a continuous processing resource whereas the communication part relies on a good synchronization with the rest of the network, and therefore an accurate timing of actions is substantial. For this purpose, we have chosen a two processor architecture that allows reuse of most of the hard- and software parts of an existing WSN system developed during the PermaSense project (Beutel et al., 2009), and gives the freedom to choose the most appropriate processing hardware for each task.

The resulting AE acquisition system therefore consists of two main blocks as shown in Fig. 2. In the data acquisition block, the two input channels are amplified, digitally sampled and processed by the slave processor. As the signal processing has to be done continuously for two channels in parallel, a processor that supports parallelism was chosen. This design allows performance of the data acquisition using direct memory access. Detected event waveforms are stored to the SD card of the slave processor, and the extracted event parameters are then forwarded to the master controller. Once the measurement campaign is over and the system is retrieved 
(a)

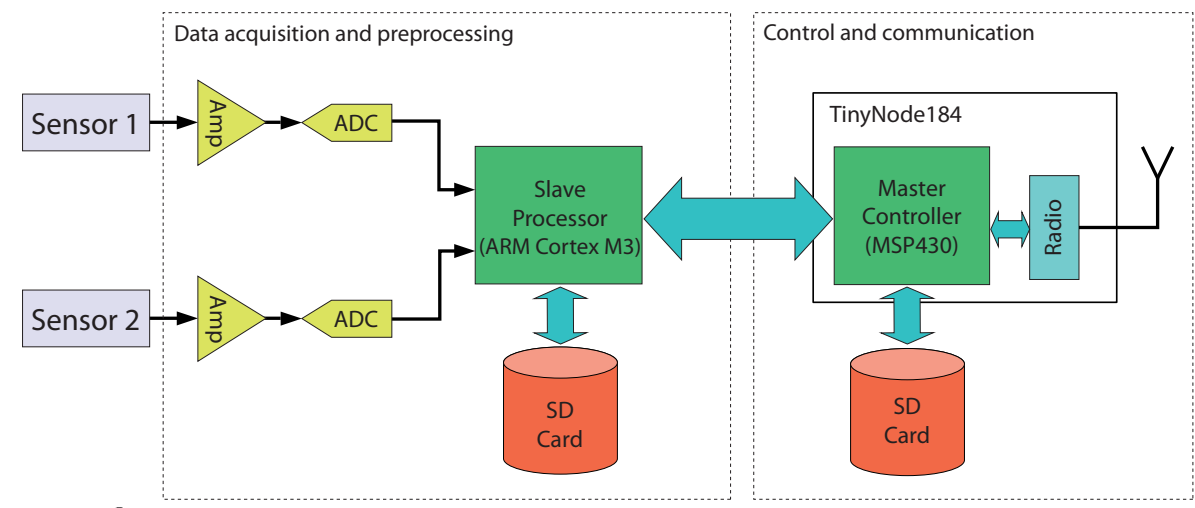

(b)

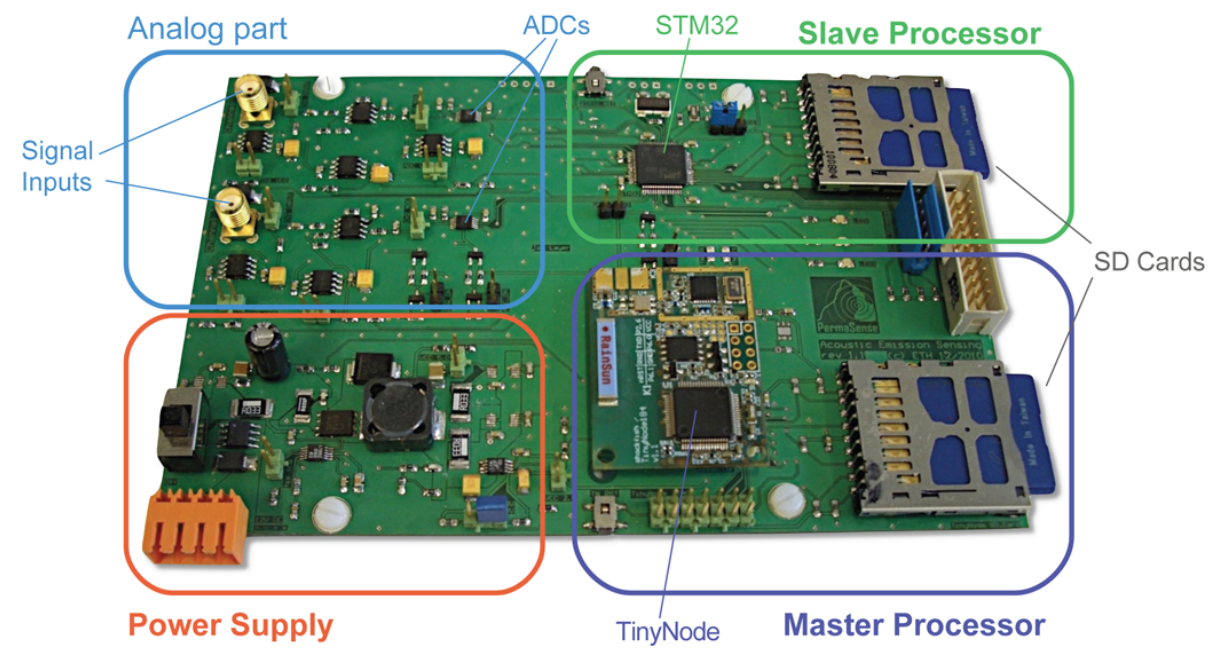

Fig. 2. (a) Block diagram of AE-node architecture and (b) electronic board.

from the field site, the waveforms stored locally on the SD card can be read out.

The controller part of the system consists of a TinyNode184 module (Shockfish SA, Switzerland). Its task is to control the data acquisition on the AE-node and to perform the WSN communication. The TinyNode184 receives $\mathrm{AE}$ parameter data from the slave processor through its serial interface. A second SD card, associated with the TinyNode184, serves as network packet backlog in case of missing network connectivity or high AE event rates. The data communication is achieved by the ultra-low power WSN protocol Dozer (Burri et al., 2007). Additional sensors are placed on the board to monitor the health of the AE-node by measuring temperature, humidity, different voltage levels and supply currents.

Ruggedization of the node is ensured by a Rose + Bopla die-cast aluminum enclosure (Phoenix Mecano AG, Switzerland). Connectors and an outdoor antenna which allow sustained submersion in water are used. A stainless steel protective shoe adds additional protection, especially from rocks falling from above.

\subsection{System performance}

In order to evaluate the performance of the AE-node under high event load and varying temperature conditions, experiments were carried out in an automatic climate chamber. As the experimental conditions shall be reproducible, the AEnode was stimulated by a synthetic test waveform electrically transmitted by means of a waveform generator (i.e. no piezoelectric transducer were used during this experiment). The test waveform simulates an $\mathrm{AE}$ event consisting of three frequency components at 35,50 and $60 \mathrm{kHz}$, with the $50 \mathrm{kHz}$ oscillations being the dominant frequency component (Fig. 3). These characteristics, further detailed in Table 2, match well with the average waveform that has been captured during the preliminary experiments (Amitrano et al., 2012). 
Table 2. Characteristics of the synthetic AE signal used to evaluate the AE-node performance, mean and standard deviation (Std. Dev.) of parameter values detected by the AE-node at $-20^{\circ} \mathrm{C}$ and $+40^{\circ} \mathrm{C}$.

\begin{tabular}{lrrrrrr}
\hline & & \multicolumn{2}{c}{ Measured at $-20{ }^{\circ} \mathrm{C}$} & & \multicolumn{2}{c}{ Measured at $+40{ }^{\circ} \mathrm{C}$} \\
\cline { 3 - 4 } \cline { 6 - 7 } Parameter & Value & Mean & Std. Dev. & & Mean & Std. Dev. \\
\hline Amplitude $(\mathrm{mV})$ & 1402 & $1332(-5.0 \%)$ & $8.6(0.6 \%)$ & & $1410(+0.5 \%)$ & $12.6(0.9 \%)$ \\
Rise time $(\mu \mathrm{s})$ & 436 & $436(+0.0 \%)$ & $0.8(0.2 \%)$ & & $436(+0.0 \%)$ & $1.0(0.2 \%)$ \\
Length $(\mu \mathrm{s})$ & 2532 & $2619(+3.4 \%)$ & $49.6(2.0 \%)$ & & $2458(-2.9 \%)$ & $21.2(0.8 \%)$ \\
Count & 73 & $76(+4.1 \%)$ & $1.3(1.8 \%)$ & & $70(-4.1 \%)$ & $0.8(0.9 \%)$ \\
Energy $\left(\mathrm{V}^{2}\right)$ & 931 & $1010(+8.5 \%)$ & $1.8(0.2 \%)$ & & $771.1(-17.0 \%)$ & $5.6(0.6 \%)$ \\
\hline
\end{tabular}

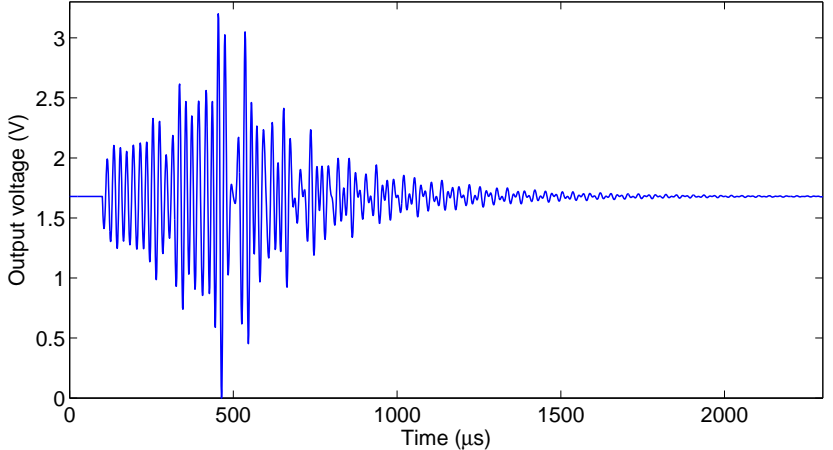

Fig. 3. Test signal generated by the waveform generator to evaluate the AE-node performance. The y-axis does not compare directly with the amplitude measured by the AE-node. During the experiment a post-trigger time of $800 \mu$ s was used.

The AE-node as well as its two preamplifiers were installed in the climate chamber where temperature varied between $-20^{\circ} \mathrm{C}$ and $+40^{\circ} \mathrm{C}$ at about $15^{\circ} \mathrm{C}$ per hour, while the waveform generator was kept at constant ambient temperature to ensure reproducible stimulation throughout the experiment. Furthermore, the generated waveform was identical for all simulated events. The system was subjected to 30-s stimulation periods at a rate of 15 events per second on each channel, followed by 5-min interruptions, over a total of $7 \mathrm{~h}$. This event load was chosen to slightly exceed the load observed during the periods of high AE activity of the pilot experiment (Amitrano et al., 2012).

The performances of the AE-node were not affected by temperature variations in terms of operational stability as well as parameterization and storage capabilities. The system constantly parameterized $95 \%$ of all generated events, and stored $85 \%$ of all waveforms. Additional tests showed that reducing the stimulation period to $15 \mathrm{~s}$ yields $100 \%$ of parameterized events and over $90 \%$ of all waveforms stored on the SD card, demonstrating the ability of the system to switch between the different granularity levels of processing. The overall power consumption of the AE-node during signal processing was $576 \mathrm{~mW}$, and did not change with temperature. This energy demand can be met with a small size solar system.
While temperature variations had no influence on data processing performances, they did affect the analog signal processing and thus the accuracy of the parameter values (Fig. 4 and Table 2). The event amplitude increases with temperature while the length and count number decrease. The most affected parameter is energy due to its quadratic nature. The rise time, on the other hand, is not sensitive at all to temperature. The precision of all measured parameters does not appear to be affected by temperature, since the standard deviation of the measured parameters, for a fixed temperature, remains small ( $\leq 2 \%$, Table 2$)$.

The significant sensitivity of most AE parameters to temperature should be accounted for during data analysis. Further tests showed that this temperature sensitivity was mostly induced by the external preamplifier of the AE-node. The results presented in Fig. 4 can be used to establish simple correction functions for the temperature dependence of $\mathrm{AE}$ parameters. The temperature recorded inside the AE-node by the TinyNode184, assumed to be representative of that of the whole AE-node, can be used to perform the correction. However, in order to gain a full understanding of the temperature sensitivity of measured parameters, further tests considering a wide range of waveform characteristics would be useful.

\section{A casing to accommodate acoustic transducers}

Capturing acoustic signals from a given depth of the rock wall requires a borehole. We have investigated two technical options for capturing the AE signal (Weber et al., 2012): (i) insertion of the transducer into the borehole or (ii) insertion of a waveguide for transmitting the signal to the rock surface, where the transducer is installed. The first solution was favored and lead to the construction of a casing which accommodates the transducer within the borehole (Fig. 5).

The casing itself is made of a thermoplastic polymer (DuPont $^{\mathrm{TM}}$ Delrin ${ }^{(}$, POM-C) tube with an external diameter of $30 \mathrm{~mm}$ and houses a piezoelectric transducer. The transducer (cylinder with $17 \mathrm{~mm}$ diameter, $17 \mathrm{~mm}$ height and a radial cable exit) is held down on the bottom assembly inside the casing by a spring. The bottom part of the casing is made of a $4 \mathrm{~mm}$ thick aluminum plate. A lid with a waterproof 


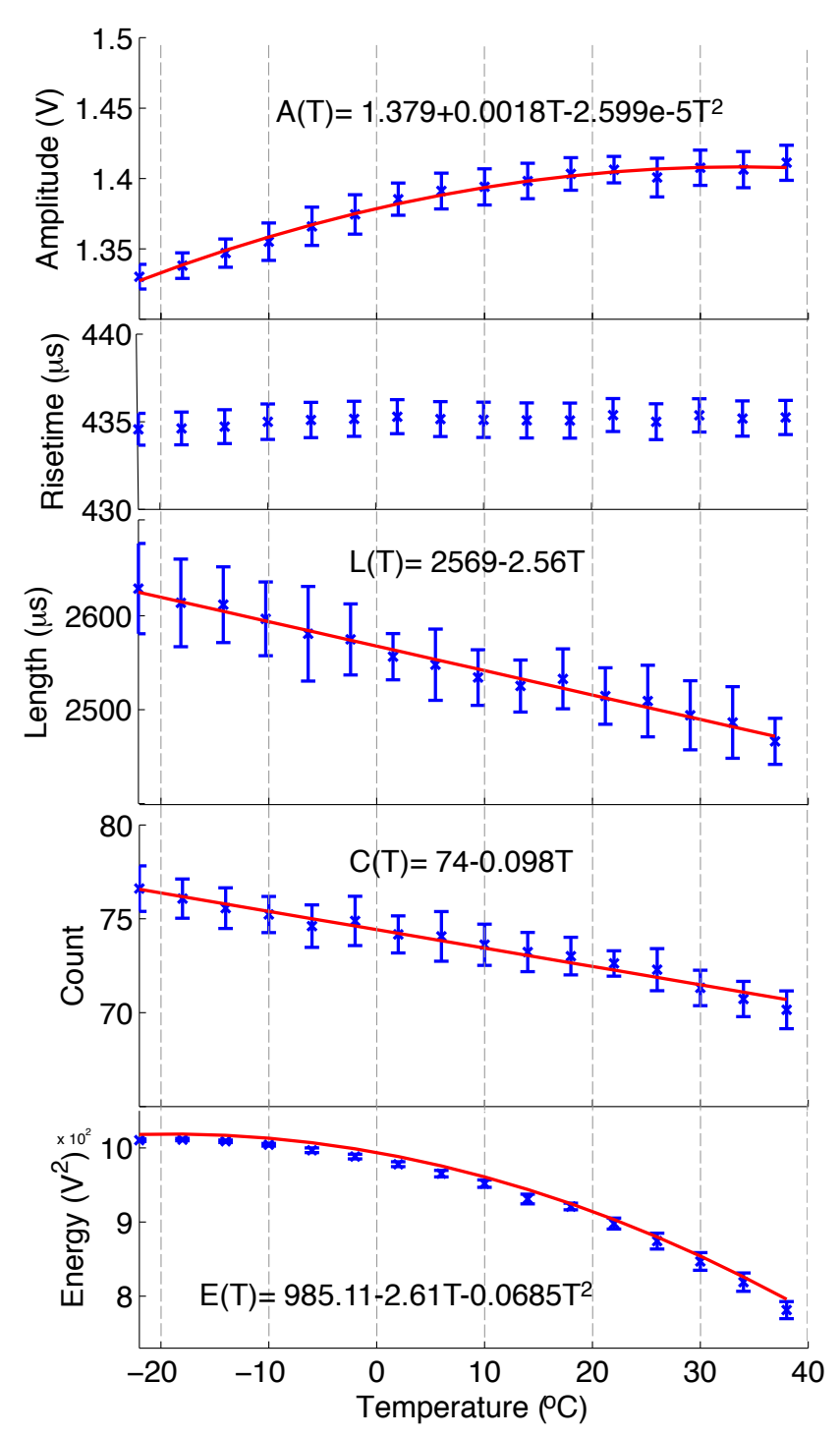

Fig. 4. Temperature dependency of measured AE signal parameters (mean and standard deviation) over a range from -20 to $40^{\circ} \mathrm{C}$. The rise time parameter remains stable, whereas all other parameters show a noticeable temperature dependence. Linear regressions with respect to temperature $(T)$ are given for the length $(L)$ and count $(C)$, while quadratic regressions are given for the amplitude $(A)$ and energy $(E)$.

cable port completes the surface end of the casing. The lid was designed so that it can easily be opened to exchange the sensor if needed, even once installed in the field. The length of the casing can be adjusted to fit the application requirements.

The choice of materials used in the construction of the casing was guided by their acoustic properties, as reported in detail by Weber et al. (2012). The bottom plate should insure a good acoustic coupling between the rock and the sensing plate of the transducer, whereas other parts of the casing should reflect or attenuate acoustic signals. We have therefore chosen aluminum as a coupling material for the bottom plate because its $\mathrm{P}$-wave speed matches well with that of crystalline rock (i.e. the rock type intended for deployment) and the interface offers a high transmission coefficient (Table 1). On the other hand, POM has been chosen because it has a much lower P-wave speed than rock and a small transmission coefficient. Finally, the construction includes an air gap between the transducer and the POM tube to further improve acoustic insulation.

As water flow in the borehole can alter moisture conditions at depth and cause spurious AE events related to freezing/thawing (Kaufmann, 1999), the borehole must be sealed after installation. This is achieved by drilling a slightly oversized borehole ( $40 \mathrm{~mm}$ diameter) for the installation of the casing within the rock wall. The casing is first fixed though its aluminum plate to the bottom of the borehole using glue. In order to seal the borehole sides, a two-component polyurethane resin (Geo-Gel, Kuempel AG, Switzerland) is used. This slow-hardening resin has a viscosity of $850 \mathrm{mPa}$ (i.e. between olive oil and liquid honey) and can be injected into the borehole after insertion of the casing. The injection of Geo-Gel fills the spacing between the casing $(30 \mathrm{~mm}$ diameter) and the borehole walls ( $40 \mathrm{~mm}$ diameter). The role of the Geo-Gel is twofold: it seals the borehole, preventing the percolation of water or ice formation on the casing, and it also further attenuates acoustic signals generated at depths different than that of the transducer (Table 1). Compared to a direct installation of the transducer on the rock surface, the signal loss due to the aluminum plate and the glue used to fix the casing is $2 \mathrm{~dB}$.

\section{Additional measurements: rock temperature and moisture content}

In order to assess what drives rock damage monitored through $\mathrm{AE}$, it is crucial to obtain simultaneous measurements of rock temperature, as well as the variation in rock liquid water content. Moisture availability has been suggested to be the limiting factor for the operation of frost weathering (Hall et al., 2002). While measuring rock temperature is quite straightforward, unattended and continuous measurements of rock moisture content are challenging. So far, no standard method has been shown to give reliable measurements of moisture at different depths over long periods (Sass, 2005). Moreover, our measurement system is intended to be deployed in low porosity rock, where a substantial measurement precision is required to detect variations in liquid water content. The measurements of moisture content should be reliable and comparable in all seasons. Hasler (2011) reported that moisture measurements based on galvanic coupling with the rock can be problematic at temperatures below $-10^{\circ} \mathrm{C}$. We have thus chosen to use a commercial probe based on capacitive coupling instead: EnviroSmart (Sentek Pty Ltd, Australia). This probe, initially designed to measure 
(a)

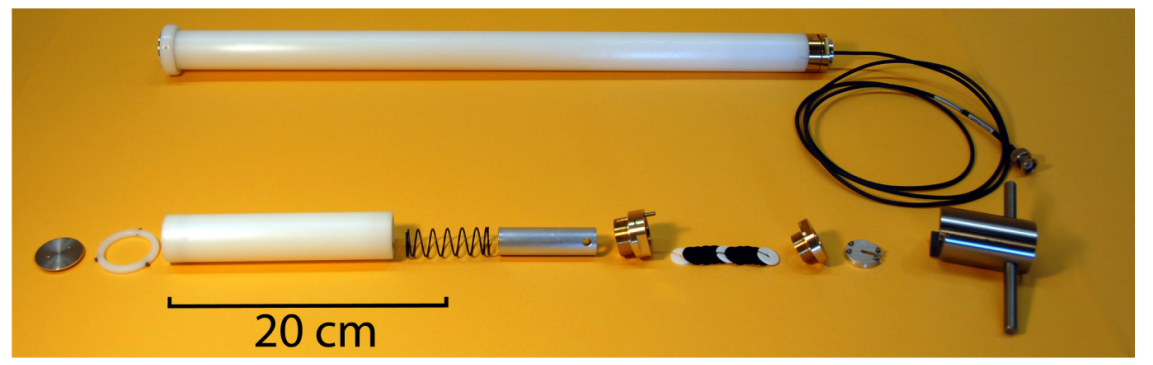

(b)

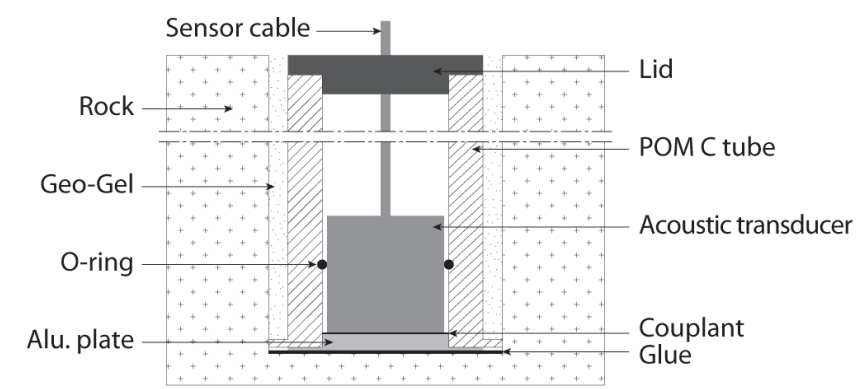

Fig. 5. (a) Picture of two copies of the AE casing, disassembled (bottom panel) and assembled (top panel). (b) Schematic view of the casing and acoustic transducer in a borehole.

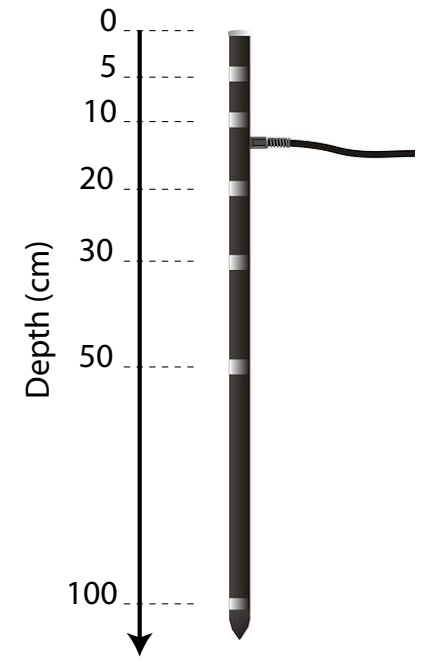

Fig. 6. Temperature probe Th3.

soil water content, is based on an electro-magnetic method in the frequency domain (Schwank et al., 2006). Considering the accuracy of the probe, these measurements will only be considered as a qualitative test, providing complementary information on relative changes rather than absolute values, to help the interpretation of the AE data.

\subsection{Temperature probe}

Temperature is measured at six different levels in the rock using a Th3 probe (Fig. 6, UMS GmbH, Germany), an instrument that was initially designed for measurements in soils. (a)

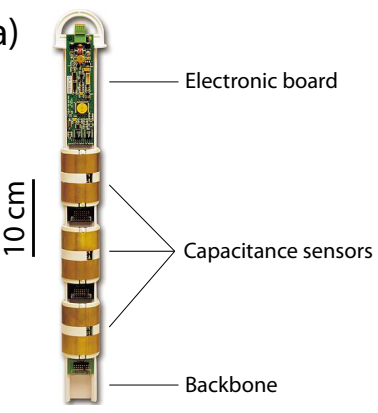

(b)

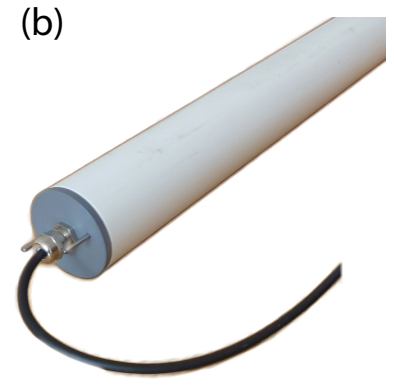

Fig. 7. (a) Capacitance probe EnviroSmart. The position of the electronic board and of sensors can be freely adjusted on the backbone; the setups used in our field deployments are described in Sect. 6 . (b) Modified access tube.

The probe is a $104 \mathrm{~cm}$ long cylinder, $2 \mathrm{~cm}$ in diameter. It is inserted into a borehole drilled perpendicular to the rock surface. The thermistors (at 5, 10, 20, 30, 50,100 cm) have an accuracy of $0.1^{\circ} \mathrm{C}$. After installation, the upper part of the borehole is sealed with silicone to avoid water infiltration.

\subsection{Capacitance probe to estimate moisture content}

The Sentek EnviroSmart probe features a string of sensors that can be placed in increments of $10 \mathrm{~cm}$ on a plastic backbone protected by a PVC plastic access tube (Fig. 7). The choice of this probe was guided by its ability to measure at different depths, its flexible design (the number of sensors and their position can be adapted), as well as the high precision stated by the vendor, $0.03 \%$ (Sentek, 2001). Laboratory 


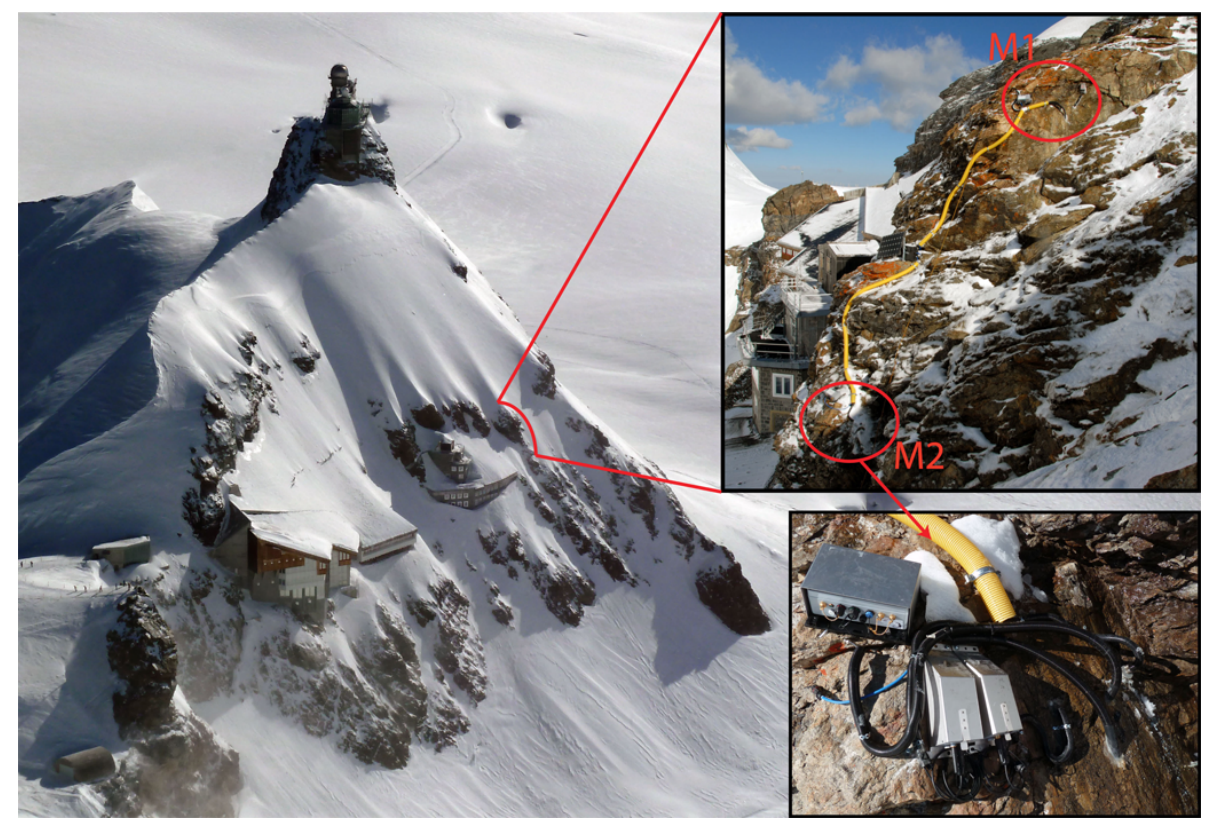

Fig. 8. Field deployment at Jungfraujoch, close-up of the measurement site, and detail of measurement system M2.

characterization studies have been carried out on the probe (Schwank et al., 2006; Evett et al., 2006), and they report a measurement accuracy of the volumetric water content up to $0.3 \%$, estimated by root mean square error. Our measurement system is initially designed to be deployed in lowporosity rock ( $\phi \simeq 1 \%$, see Sect. 6$)$. In these conditions, the high ratio of measurement precision to rock porosity suggests that it is not possible to establish a proper calibration curve. However, the measurement signal can still be expected to reflect (though with limitations) variations in liquid water content. Therefore, we have chosen to use the raw data produced by the probe as a qualitative index of primarily temporal variations in rock liquid water content.

The method used by the EnviroSmart probe consists in measuring the dielectric constant through the electric capacitance of the surrounding material submitted to an electrical field in the radio-frequency range $(100-150 \mathrm{Mhz})$. Due to the large contrast between the dielectric constants of water and that of other constituents (e.g. air, ice or rock), the dielectric constant of the porous medium can be used as a surrogate for its water content.

Each sensor of the probe operates as an inductor-capacitor oscillator, and the sensor readings are proportional to their resonant frequency, which is a function of the capacitance of the surrounding material. Each sensor is normalized to yield readings $N=1$ in water and $N=0$ in air, at $25^{\circ} \mathrm{C}$. As explained above, it does not seem realistic to try to estimate a proper calibration curve for the low-porosity rock where we intend to deploy the measurement system. Instead, the variations of normalized sensor readings $N^{k}$ are considered in our measurement system as a qualitative index of variations

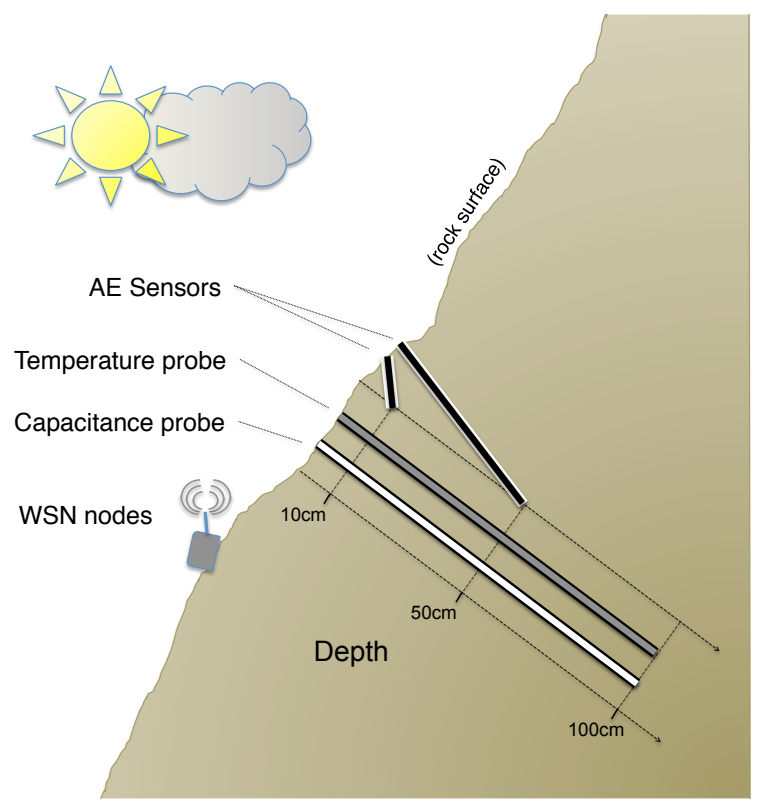

Fig. 9. Schematic view of the field setup of the measurement system.

in liquid water content. Regarding the volume of rock that is sensed by the probe, Schwank et al. (2006) reported that $80 \%$ and $90 \%$ of the signal is sensed within 20 and $37 \mathrm{~mm}$ of the access tube, respectively. Measurements of the EnviroSmart probe are sensitive to temperature, however this sensitivity was shown to be independent of the type of media surrounding the probe (Evett et al., 2006). In order to estimate a linear correction for the temperature dependence of 


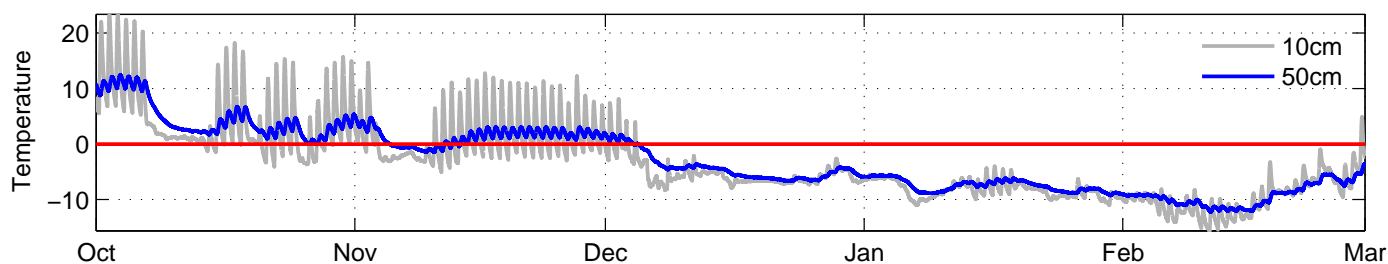

Fig. 10. Rock temperatures measured at M1.

(a)
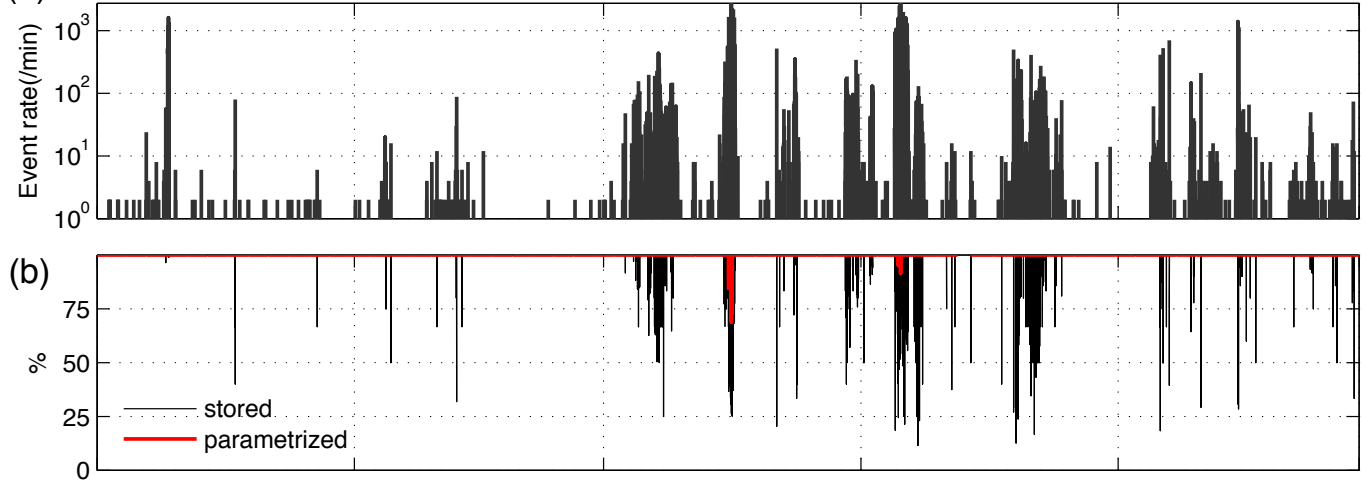

(c)

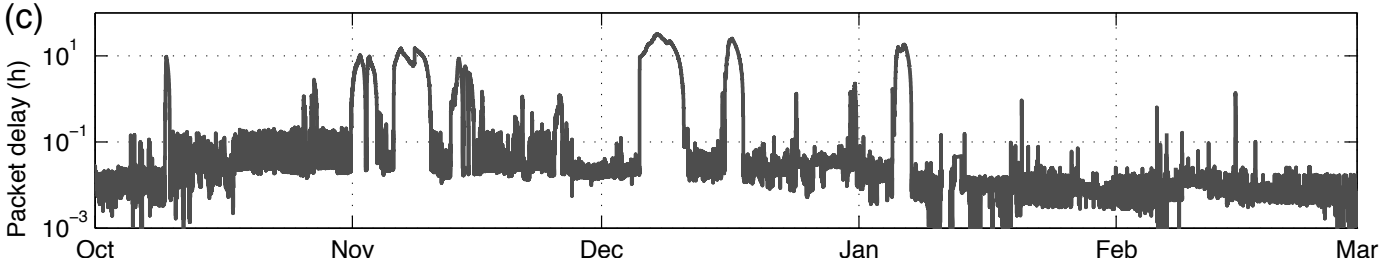

Fig. 11. Performance of the AE-node at M1: (a) rate of AE events measured, (b) percentage of all measured events that were parameterized, and fully stored (waveform), and (c) time elapse between generation of data packets and their transmission through the WSN.

the measurements, we use data measured over short periods, above freezing, during which moisture content is assumed to be constant.

The probe is installed in the rock wall using a borehole that is sealed using a similar method as for the AE casing (see Sect. 4 ) in order to exclude water flow between the probe and the borehole walls.

\section{A first field deployment}

\subsection{Deployment of two systems}

During the course of summer 2011, two measurement systems were deployed in complementary locations on a rock wall close to the Jungfraujoch, in the central Swiss Alps (Fig. 8). The deployment site is a south-facing, 50-70 ${ }^{\circ}$ steep cliff of crystalline rock that is situated at an elevation of $3500 \mathrm{~m}$ a.s.l. The local mean annual air temperature is about $-7.3^{\circ} \mathrm{C}$ (1961-1990), whereas mean annual rock temperatures near the surface are between -2 and $-3{ }^{\circ} \mathrm{C}$ in this south face (Hasler et al., 2011). The site is next to the high-altitude research station Jungfraujoch and can thus be accessed yearround by train.

The locations chosen to deploy the two measurement systems are about ten meters apart and show similar general characteristics. The main difference between these two locations lies in the availability of liquid water. The first measurement system, later referred to as $\mathrm{M} 1$, is on a rather dry spur-like feature, while the second one (M2) is in a gullylike depression that is prone to collect melt water from snow patches above.

A small platform was deployed during the installation period to facilitate the work in this steep environment. Boreholes were drilled using a diamond crown drill. The insertion of the probes into the boreholes was performed under dry conditions and the boreholes were further dried out using a hot-air blower. Both measurement systems are composed of a two-channel AE-node as well as a temperature and EnviroSmart probe, where probes are separated from each other by about ten centimeters (Fig. 9). The AE casings are installed so that the sensing parts are located at 10 and $50 \mathrm{~cm}$ depth. At location M1, the EnviroSmart probe was setup to measure 


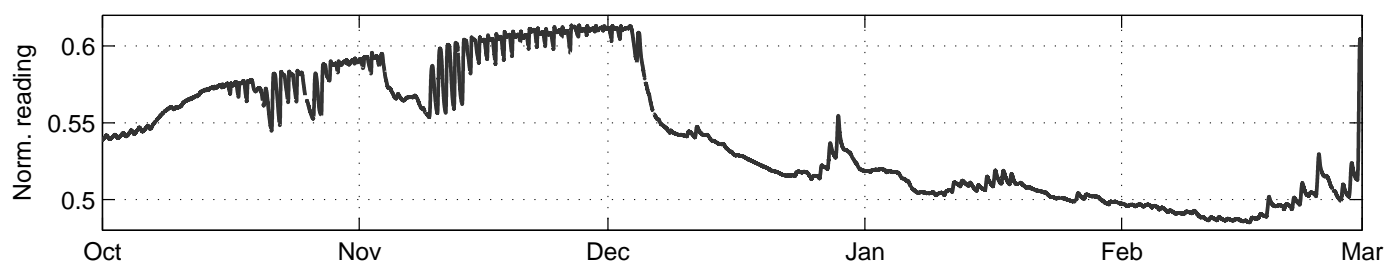

Fig. 12. Normalized sensor reading of the EnviroSmart probe at $20 \mathrm{~cm}$ depth (M1).

at $10,20,30,50$ and $100 \mathrm{~cm}$; whereas at location M2, difficulties during the drilling operation forced us to rearrange the probe to a shorter configuration measuring at 10,20 and $50 \mathrm{~cm}$ depth, only. Rock porosity was estimated from the drill cores to be around $1-2 \%$.

\subsection{System performance}

Since the end of the installation work in September 2011, measurement system M1 has been operating continuously, while at M2, the AE-node has encountered software problems related to communication errors. The software bug causing these problems has been fixed, and both AE-nodes were updated with the new software version in January 2012. Both systems are, to date, running. Here, however, we only briefly report data measured by M1, where a five-month time series has already been acquired.

Measurements obtained between September 2011 and February 2012 are summarized in Figs. 10, 11 and 12, respectively giving the rock temperature, the AE-node performance, and a sample of the capacitance measurements. During this period, $10^{7} \mathrm{AE}$ events were detected by both channels of M1, with maximum rates reaching 50 events per second on a single channel. This corresponds to the maximal rate of events that the AE-node can measure.

Very little AE activity was detected during periods of positive temperatures, whereas it increases during freezing periods, occurring in intermittent bursts separated by periods of quiescence of varying lengths. The strategy of capturing AE events with different granularity level operates well; during the periods of intense $\mathrm{AE}$ activity, the rate of stored events decreases significantly, but a fraction of the waveforms are still saved, which is important for further analyses. It is only during the largest bursts of activity that the AE-node cannot parameterize all events (Fig. 11). The maximal amplitude of $\mathrm{AE}$ events ranged from $35 \mathrm{~dB}$ (corresponding to the threshold) to $83 \mathrm{~dB}$. In comparison, the absolute maximal amplitude that the system can detect is $93 \mathrm{~dB}$.

Figure 12 reports the time series of readings from one of the sensors of the EnviroSmart probe. Measurements during the first two months show an increasing trend probably due to a re-equilibration of the moisture conditions around the borehole, which was artificially dried-out using a hot air blower before installing the probe.

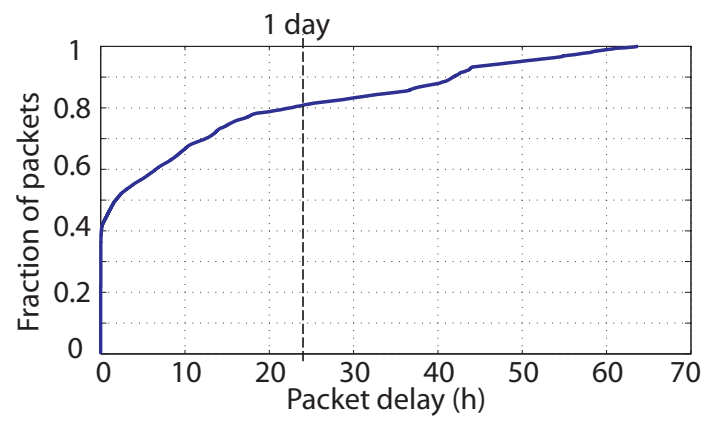

Fig. 13. CDF of packet delays, for packets generated by the two AEnodes. More than $80 \%$ of all packets are forwarded to the network sink in less than $24 \mathrm{~h}$.

The existing WSN was originally intended to transport constantly generated low-data-rate sensor data. The AE system exposed the WSN to a different data pattern. The performance of the network can be illustrated by means of the observed packet delay (Fig. 11c). In periods of high AE activity, the limited bandwidth of the network becomes noticeable. During the five-month period reported here, all data packets had been routed through the network with a maximum latency of $64 \mathrm{~h}$, while $80 \%$ of the data was routed in less than one day (Fig. 13). The observed network behavior demonstrates that the existing WSN infrastructure is capable of supporting highly variable network traffic. More generally, these preliminary results demonstrate the operability of the measurement system in field conditions.

\section{Conclusions}

We have presented a custom AE platform designed for continuous monitoring of AEs in rock walls under harsh environmental conditions. The novelty of the system lies in its simplicity and robustness, as well as its integration with a modern WSN. This architecture allows monitoring of AEs from different positions that can be freely chosen within a range up to a few hundred meters from the main station of the WSN. The first field deployment showed that the ability to check in near real-time the acquired data, combined with the possibility of remotely adjusting the AE detection threshold, were useful functionalities. In our case, these functionalities 
allowed us to find the optimal threshold for each monitored position.

Although our initial application of the monitoring system aims to support fundamental research on processes that damage rock under cold climate, the system could equally serve other applications on mountain rock walls or concrete structures. In the context of rock fall hazard surveillance, for example, the $\mathrm{AE}$ technique was reported to have the highest potential for subsurface monitoring compared to other existing methods (Arosio et al., 2009). The requirements of such an application are already fulfilled by our measurement system; a network of spatially distributed AE-nodes could be used to monitor the critical or unstable positions of the rock wall, providing reliable data in near real-time. Finally, the monitoring system presented in this paper could also cover a number of other applications that demand long-term monitoring of damage increase in geomaterial. In concrete and masonry, for example, frost (Coussy, 2005) and salt crystallization (Noiriel et al., 2010) are important sources of damage that can affect the stability of structures and buildings.

Acknowledgements. The research presented was supported though the project PermaSense funded by the Swiss National Foundation (SNF) NCCR MICS as well as the International Foundation High Altitude Research Stations Jungfraujoch and Gornergrat. We acknowledge support from the PermaSense team, A. Hasler, J. Nötzli, T. Gsell, L. Böckli, and the workshop of the Physics Institute at UZH, most specifically for the dedication and creativity of R. Maier. The support of Bletry AG, Switzerland, for the drilling operation is greatly appreciated as well as fruitful discussions with D. Amitrano. L. Girard is supported by a Forschungskredit grant of $\mathrm{UZH}$.

\section{Edited by: M. Genzer}

\section{References}

Amitrano, D., Gaffet, S., Malet, J.-P., and Maquaire, O.: Understanding mudslides through micro-seismic monitoring: The Super-Sauze (South French Alps) case study, Bulletin de la Société Géologique de France, 178, 149-157, doi:10.2113/gssgfbull.178.2.149, 2007.

Amitrano, D., Arattano, M., Chiarle, M., Mortara, G., Occhiena, C., Pirulli, M., and Scavia, C.: Microseismic activity analysis for the study of the rupture mechanisms in unstable rock masses, Nat. Hazards Earth Syst. Sci., 10, 831-841, doi:10.5194/nhess10-831-2010, 2010.

Amitrano, D., Gruber, S., and Girard, L.: Rock damage inferred from acoustic emissions in a partly frozen high-alpine rock-wall, Earth Planet. Sc. Lett., 341, 86-93, 2012.

Arosio, D., Longoni, L., Papini, M., Scaioni, M., Zanzi, L., and Alba, M.: Towards rockfall forecasting through observing deformations and listening to microseismic emissions, Nat. Hazards Earth Syst. Sci., 9, 1119-1131, doi:10.5194/nhess-9-1119-2009, 2009.
Beutel, J., Gruber, S., Hasler, A., Lim, R., Meier, A., Plessl, C., Talzi, I., Thiele, L., Tschudin, C., Woehrle, M., and Yuecel, M.: PermaDAQ: A scientific instrument for precision sensing and data recovery in environmental extremes, 2009 International Conference on Information Processing in Sensor Networks, IEEE, New York, 2009.

Burri, N., von Rickenbach, P., and Wattenhofer, R.: Dozer: ultralow power data gathering in sensor networks, in: Proc. 6th Int'l Conf. Information Processing Sensor Networks (IPSN'07), ACM Press, New York, 450-459, April 2007.

Cheon, D.-S., Jung, Y.-B., Park, E.-S., Song, W.-K., and Jang, H.I.: Evaluation of damage level for rock slopes using acoustic emission technique with waveguides, Eng. Geol., 121, 75-88, doi:10.1016/j.enggeo.2011.04.015, 2011.

Coussy, O.: Poromechanics of freezing materials, J. Mech. Phys. Solids, 53, 1689-1718, 2005.

Dixon, N., Hill, R., and Kavanagh, J.: Acoustic emission monitoring of slope instability: development of an active waveguide system, Geotech. Eng., 156, 83-95, 2003.

Evett, S. R., Tolk, J. A., and Howell, T. A.: Soil profile water content determination: sensor accuracy, axial response, calibration, temperature dependence, and precision, Vadose Zone J., 5, 894-907, 2006.

Gaffet, S., Guglielmi, Y., Cappa, F., Pambrun, C., Monfret, T., and Amitrano, D.: Use of the simultaneous seismic, GPS and meteorological monitoring for the characterization of a large unstable mountain slope in the southern French Alps, Geophys. J. Int., 182, 1395-1410, 2010.

Grosse, C., McLaskey, G., Bachmaier, S., Glaser, S. D., and Krügera, M.: A hybrid wireless sensor network for acoustic emission testing in SHM, in: Proc. SPIE Sensors and Smart Structures Technol. Civil, Mech. Aerosp. Syst., 6932, 69323-8-693238-9, 2008.

Gruber, S. and Haeberli, W.: Permafrost in steep bedrock slopes and its temperature-related destabilization following climate change, J. Geophys. Res., 112, F02S18, doi:10.1029/2006JF000547, 2007.

Hall, K., Thorn, C. E., Matsuoka, N., and Prick, A.: Weathering in cold regions: some thoughts and perspectives, Prog. Phys. Geogr., 24, 577-603, 2002.

Hardy, H.: Acoustic emission/microseismic activity - principles, techniques and geotechnical applications, A. A. Balkema, Lisse, The Netherlands, 2003.

Hasler, A.: Thermal conditions and kinematics of steep bedrock permafrost, Ph.D. thesis, University of Zürich, Switzerland, 2011.

Hasler, A., Gruber, S., and Haeberli, W.: Temperature variability and offset in steep alpine rock and ice faces, The Cryosphere, 5, 977-988, doi:10.5194/tc-5-977-2011, 2011.

Helmstetter, A. and Garambois, S.: Seismic monitoring of Séchilienne rockslide (French Alps): Analysis of seismic signals and their correlation with rainfalls, J. Geophys. Res., 115, F03016, doi:201010.1029/2009JF001532, 2010.

Kaufmann, J.: Experimental identification of damage mechanisms in cementitious porous materials on phase transition of pore solution under frost deicing salt attack, Ph.D. Thesis, EPFL Lausanne, Switzerland, 1999.

Lacroix, P. and Helmstetter, A.: Location of Seismic Signals Associated with Microearthquakes and Rockfalls on the Sechilienne Landslide, French Alps, Bull. Seismol. Soc. Am., 101, 341-353, 
doi:10.1785/0120100110, 2011.

Ledeczi, A., Hay, T., Volgyesi, P., Hay, D. R., Nadas, A., and Jayaraman, S.: Wireless acoustic emission sensor network for structural monitoring, IEEE Sens. J., 9, 1370-1377, 2009.

Levy, C., Jongmans, D., and Baillet, L.: Analysis of seismic signals recorded on a prone-to-fall rock column (Vercors massif, French Alps), Geophys. J. Int., 186, 296-310, doi:10.1111/j.1365246X.2011.05046.x, 2011.

Lockner, D. A., Byerlee, J. D., Kuskenko, V., Ponomarev, A., and Sidorin, A.: Quasi-static fault growth and shear fracture energy in granite, Nature, 350, 39, 39-42, doi:10.1038/350039a0, 1991.

Matsuoka, N. and Murton, J. B.: Frost weathering: recent advances and future directions, Permafrost Periglac., 19, 195-210, 2008.

Michlmayr, G., Cohen, D., and Or, D.: Sources and characteristics of acoustic emissions from mechanically stressed geologic granular media - A review, Earth-Sci. Rev., 112, 97-114, 2012.

Murton, J. B., Peterson, R., and Ozouf, J. C.: Bedrock fracture by ice segregation in cold regions, Science, 314, 1127-1129, 2006.

Noiriel, C., Renard, F., Doan, M., and Gratier, J. P.: Intense fracturing and fracture sealing induced by mineral growth in porous rocks, Chem. Geol., 269, 197-209, 2010.

Sass, O.: Rock moisture measurements: techniques, results, and implications for weathering, Earth Surf. Proc. Land., 30, 359-374, 2005.
Scholz, C. H.: Microfracturing and inelastic deformation of rock in compression, J. Geophys. Res., 73, 1417-1432, doi:10.1029/JB073i004p01417, 1968.

Schwank, M., Green, T. R., Matzler, C., Benedickter, H., and Fluhler, H.: Laboratory characterization of a commercial capacitance sensor for estimating permittivity and inferring soil water content, Vadose Zone J., 5, 1048-1064, 2006.

Sentek: Calibration of Sentek Pty. Ltd. soil moisture sensors, Sentek SA, Australia, 2001.

Walder, J. and Hallet, B.: A theoretical model of the fracture of rock during freezing, Geol. Soc. Am. Bull., 96, 336-346, 1985.

Walter, M., Arnhardt, C., and Joswig, M.: Seismic monitoring of rockfalls, slide quakes, and fissure development at the Super-Sauze mudslide, French Alps, Eng. Geol., 128, 12-22, doi:10.1016/j.enggeo.2011.11.002, 2012.

Weber, S., Gruber, S., Girard, L., and Beutel, J.: Design of a measurement assembly to study in-situ rock damage driven by freezing, Proceeding of the 10th Int. Conference on Permafrost, Salekhard, Russia, 2012. 